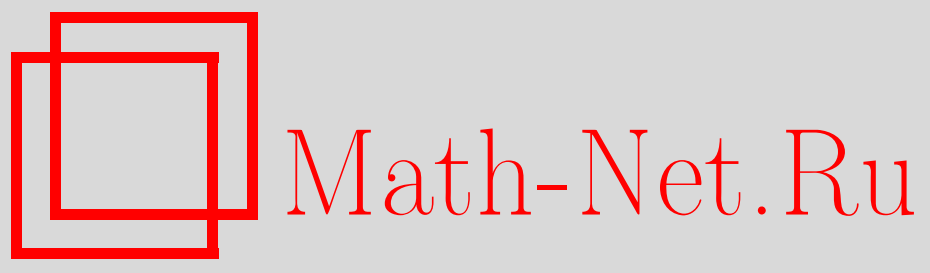

В. П. Радченко, В. В. Лунин, А. П. Морозов, Исследование кинетики физико-механических параметров упрочнённых образцов из сплавов В95 и Д16Т вследствие температурных выдержек и многоцикловых усталостных испытаний, Вестн. Сам. гос. техн. ун-та. Сер. Физ.-мат. науки, 2012, выпуск 1(), 123132

DOI: https://doi.org/10.14498/vsgtu1059

Использование Общероссийского математического портала Math-Net.Ru подразумевает, что вы прочитали и согласны с пользовательским соглашением

http://www.mathnet.ru/rus/agreement

Параметры загрузки:

IP: 3.95 .254 .165

26 апреля 2023 г., 11:27:50

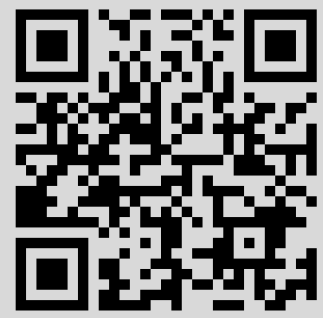


Вестн. Сам. гос. техн. ун-та. Сер. Физ.-мат. науки. 2012. № 1 (26). С. $123-132$

УДК 621.787:539.319

\title{
ИССЛЕДОВАНИЕ КИНЕТИКИ ФИЗИКО-МЕХАНИЧЕСКИХ ПАРАМЕТРОВ УПРОЧНЁННЫХ ОБРАЗЦОВ ИЗ СПЛАВОВ В95 И Д16Т ВСЛЕДСТВИЕ ТЕМПЕРАТУРНЫХ ВЫДЕРЖЕК И МНОГОЦИКЛОВЫХ УСТАЛОСТНЫХ ИСПЫТАНИЙ
}

\author{
В.П. Радченко, В.В. Лунин, А.П. Морозов
}

Самарский государственный технический университет,

443100, Россия, Самара, ул. Молодогвардейская, 244.

E-mails: radch@samgtu.ru; luloon@mail.ru, andre15@inbox.ru

\begin{abstract}
Исследована кинетика остаточных напряжений и физико-механических параметров упрочнённого пневмодробеструйной обработкой слоя гладких образцов и образцов с полукруглыми надрезами из алюминиевых сплавов В95 и Д16Т вследствие температурных выдержек и многоцикловых усталостных испытаний. Исследование выполнено для симметричного иикла нагружения в условиях изгиба и растяжения-сжатия и базы испытаний-107 ииклов. Экспериментально и расчётным путём установлено увеличение приращения предела выносливости упрочнённых деталей с конщентраторами напряжений по сравнению с неупрочнёнными образцами. Показано, что термоэкспозиция приводит к релаксаиии остаточных напряжений и снижению приращения предела выносливости. Установлено, что поверхностное пластическое упрочнение значительно влияет на рост микротвёрдости по сравнению с неупрочнённым образцом. После температурных выдержек происходит падение микротвёрдости до значений, соответствующих неупрочнённому образиу. Поверхностное упрочнение повышает параметры шероховатости слоя, а дальнейшая температурная выдержка и усталостные испытания не оказывают влияния на данные параметры. Наблюдается соответствие расчётных и экспериментальных данных.
\end{abstract}

Ключевые слова: поверхностное упрочнение, цилиндрический образеи, полукруглый надрез, остаточные напряжения, предел сопротивления усталости, температурная выдержка, микротвёрдостъ, шероховатость, дебормационное упрочнение.

Введение. Прямые экспериментальные и теоретические исследования напрямую устанавливают связь между поверхностным пластическим деформированием и увеличением характеристик многоцикловой усталости [1-9], при этом отмечается решающая роль именно сжимающих остаточных напряжений. Однако в [8] отмечается, что напряженное поле, сфомированное упрочняющей обработкой, создает своего рода барьер движению дислокаций к поверхности. Этот механизм поверхностной блокировки содействует повышению малоцикловой прочности. Таким образом, при упрочнении проявляется благоприятное влияние двух факторов: сжимающих остаточных напряжений, с одной стороны, и появления в поверхностном слое особой структуры металла за счёт динамики упрочнения, - с другой стороны. Поэтому исследование эффективности упрочнения должно развиваться не только в направлении изучения влияния остаточных напряжений, например, на по-

Владимир Павлович Радченко (д.ф.-м.н., проф.), зав. кафедрой, каф. прикладной математики и информатики. Валентин Валентинович Лунин, аспирант, каф. прикладной математики и информатики. Андрей Павлович Морозов, студент, каф. прикладной математики и информатики. 
вышение сопротивления усталости, но и в направлении изучения физикомеханических характеристик материала упрочнённого слоя. Поэтому исследование, например, шероховатости поверхности, ее микротвёрдости, степени и глубины деформационного упрочнения, величины остаточных напряжений и многих физических параметров, связанных с искажением кристаллической решетки, плотностью дислокаций, является актуальной задачей. В частности, в работе [10] изучено влияние режимов пневмодробеструйной обработки на остаточные напряжения и предел выносливости плоских образцов из сплава ЭИ698ВД (ХН73МБТЮ-ВД). Испытания на усталость производились по схеме изгиба консольно закреплённой балки, при этом поперечная циклическая нагрузка прикладывалась на незакреплённом конце образца. В работе [11] эти же образцы были экспериментально исследованы по параметрам микротвёрдости и шероховатости. В результате установлено следующее:

1) упрочнение приводит к повышению параметров шероховатости по сравнению с неупрочнённым образцом;

2) микротвёрдость упрочнённых образцов существенно выше микротвёрдости на неупрочнённых образцах, что, по-видимому, связано с наличием значительных сжимающих остаточных напряжений в упрочнённом слое;

3) усталостные испытания не оказывают существенного влияния на шероховатость поверхности;

4) после завершения усталостных испытаний имеется неоднородное распределение микротвёрдости по длине образца, при этом значение микротвёрдости увеличивается от консольно закреплённого конца к свободному концу балки, что, по-видимому, объясняется частичной релаксацией остаточных напряжений в силу накопления повреждённости в материале от действия изгибных напряжений, которые имеют максимальные значения в области консольно закреплённого конца.

Целью настоящей работы является комплексный анализ и систематизация результатов исследований по влиянию режимов пневмодробеструйной обработки (ПДО) и последующих термоэкспозиции (температурной выдержки без нагрузки) и многоцикловых усталостных испытаний на кинетику остаточных напряжений и металлофизические характеристики поверхностного слоя цилиндрических образцов из алюминиевых сплавов В95 и Д16Т по данным работ $[9,12]$.

1. Экспериментальное исследование кинетики остаточных напряжений вследствие температурных выдержек и многоцикловых усталостных испытаний. Гладкие образцы диаметром 15 мм с отверстием 5 мм подвергались пневмодробеструйной обработке дробью диаметром 1,5-2 мм при давлении воздуха 0,25 МПа в течение 10 минут. Затем на половину упрочнённых и неупрочнённых гладких образов наносились круговые надрезы полукруглого профиля двух радиусов $R=0,3$ мм и $R=0,5$ мм. Остаточные напряжения в гладких образцах определялись экспериментально методом колец и полосок [13], а в образцах с надрезом - суммированием дополнительных напряжений, возникающих при нанесении надрезов на упрочнённую поверхность, с остаточными напряжениями гладких образцов [6]. Распределение осевых $\sigma_{z}$ остаточных напряжений по толщине поверхностного слоя $a$ в гладких и надрезанных образцах представлено на рис. 1. 


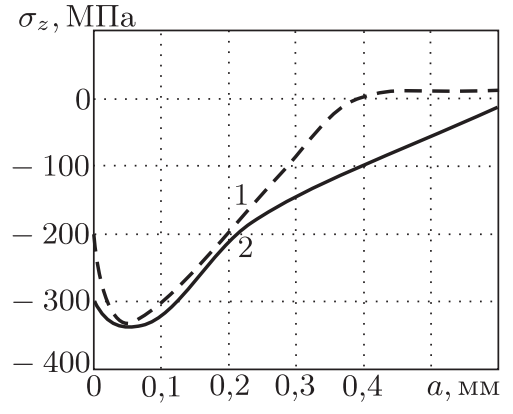

a

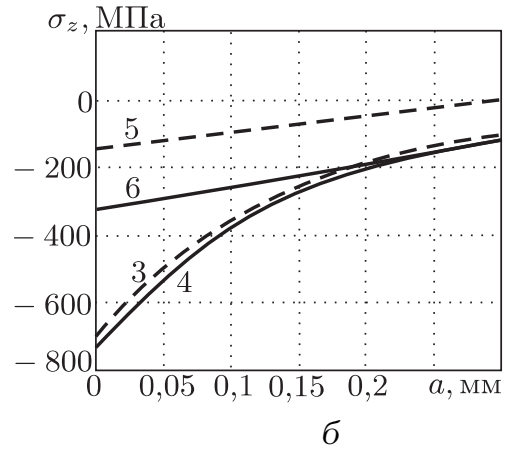

б

Рис. 1. Осевые остаточные напряжения $\sigma_{z}$ в упрочнённых ПДО гладких образцах (а) и в образцах с надрезом (б) из сплавов В95 $(1,3,5)$ и Д16Т $(2,4,6): 3,4-R=0,3$ мм; $5,6-$ $R=0,5$ мм

Испытания образцов с надрезом на усталость при чистом изгибе в случае симметричного цикла проводились на машинах МУИ-6000, база испытаний $10^{7}$ циклов нагружения. Результаты определения предела выносливости $\sigma_{-1}$ представлены в табл. 1.

Из представленных в табл. 1 данных видно, что для упрочнённых образцов с надрезом из алюминиевых сплавов В95 и Д16Т происходит существенное повышение предела выносливости $\sigma_{-1}$.

Далее половина упрочнённых и неупрочнённых образцов подвергалась термоэкспозиции (ТЭ) при температуре $T=125^{\circ} \mathrm{C}$ в течение 100 часов. Потом на гладкие образцы наносились надрезы полукруглого профиля двух радиусов $R=0,3$ мм и $R=0,5$ мм.

Остаточные напряжения в образцах определялись так же, как и в образцах до термоэкспозиции. Эпюры осевых остаточных напряжений в стандартной цилиндрической системе координат по толщине поверхностного слоя $a$ в гладких и надрезанных образцах после термоэкспозиции представлены на рис. 2. Из приведённого на рис. 2 распределения остаточных напряжений видно, что после термоэкспозиции в образцах из обоих сплавов происходит релаксация остаточных напряжений, при этом в образцах из сплава В95 сжимающие остаточные напряжения значительно меньше, чем в образцах из сплава Д16Т.

Испытания на усталость образцов с надрезом при чистом изгибе в случае симметричного цикла с учетом термоэкспозиции проводились при $T=20^{\circ} \mathrm{C}$ также на машинах МУИ-6000, база испытаний $-10^{7}$ циклов нагружения. Результаты испытаний на усталость и определения остаточных напряжений представлены в табл. 1.

Таблица 1

Результаты испытаний образцов после ПДО и термоэкспозиции

\begin{tabular}{c|c|c|c|c}
\hline \multirow{2}{*}{ Материал } & Радиус & \multicolumn{3}{|c}{$\sigma_{-1}$, МПа } \\
\cline { 4 - 5 } & надреза & Неупрочнённые & \multicolumn{2}{|c}{ Упрочнённые образцы } \\
\cline { 4 - 5 } & \multirow{2}{*}{ В95 му } & образцы & без термоэкспозиции & с термоэкспозицией \\
\hline \multirow{2}{*}{ Д16Т } & 0,3 & 105 & 200,0 & 155,0 \\
& 0,5 & 107,5 & 132,5 & 115,0 \\
& 0,3 & 82,5 & 182,5 & 175,0 \\
& 0,5 & 82,5 & 157,5 & 150,0 \\
\hline
\end{tabular}




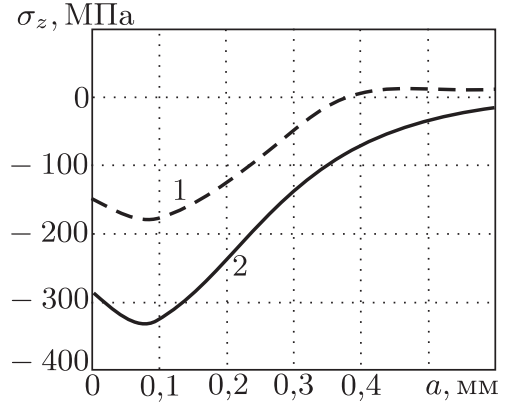

a

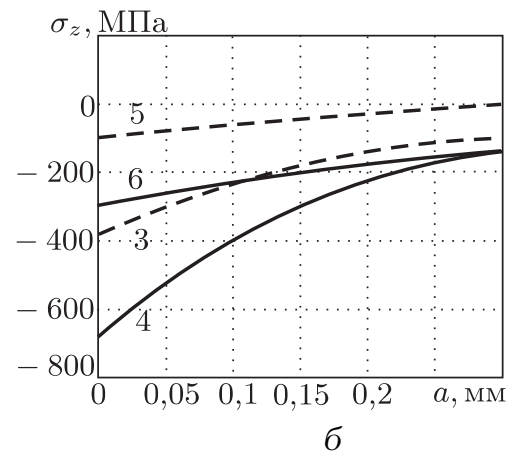

б

Рис. 2. Осевые остаточные напряжения $\sigma_{z}$ после ПДО и термоэкспозиции в гладких образцах (а) и в образцах с надрезом (б) из сплавов В95 $(1,3,5)$ и Д16Т $(2,4,6): 3,4-$ $R=0,3$ мм; $5,6-R=0,5$ мм

Сравнивая последние столбцы табл. 1, видно,что происходит падение предела выносливости $\sigma_{-1}$ после термоэкспозиции, что, по-видимому, можно объяснить релаксацией остаточных напряжений вследствие ползучести материала, поскольку приращение предела выносливости $\Delta \sigma_{-1}$, согласно $[4-7,9]$ определяется по формуле

$$
\Delta \sigma_{-1}=\psi_{\sigma}\left|\bar{\sigma}_{\text {ост }}\right|,
$$

где $\psi_{\sigma}$ - феноменологический коэффициент влияния остаточных напряжений на предел выносливости (для исследуемых материалов среднее значение этого коэффициента $\left.\psi_{\sigma}=0,36[9]\right)$,

$$
\bar{\sigma}_{\mathrm{oCT}}=\frac{2}{\pi} \int_{0}^{1} \frac{\sigma_{z}(\xi)}{\sqrt{1-\xi^{2}}} d \xi
$$

$\sigma_{z}(\xi)$ - осевые остаточные напряжения в наименьшем сечении детали с концентратором; $\xi=a / t_{\mathrm{kp}}$ - расстояние от дна концентратора до текущего слоя; $t_{\text {кр }}$ - критическая глубина нераспространяющейся трещины усталости, возникающей при работе детали на пределе выносливости (феноменологический параметр).

Таким образом, результаты экспериментальных исследований свидетельствуют об отрицательном эффекте термоэкспозиции на величину остаточных напряжений и на приращение предела выносливости.

2. Исследование металлофизических характеристик упрочнённого слоя. Внешний вид разрушенных образцов представлен на рис. 3.

Рассматривались образцы как после пневмодробеструйной обработки, так и после пневмодробеструйной обработки с последующей термоэкспозицией в течение 100 ч при температуре $125^{\circ} \mathrm{C}$. На упрочнённых образцах и образцах, прошедших термоэкспозицию, были проведены усталостные испытания на базе $10^{7}$ циклов. Табл. 2 содержит основную информацию по исходным характеристикам образцов.

На исследуемых образцах с помощью микротвердомера MM6 фирмы Leitz осуществлялось измерение микротвёрдости по Кнуппу. На разрушенных и неразрушенных образцах измерение микротвёрдости проводилось в зоне 1 и зоне 2 (см. рис. 3). Следует отметить, что допускается незначительная погрешность в полученных результатах, так как в зоне 2 влияние на точность 
Таблица 2

Исходные характеристики образцов

\begin{tabular}{|c|c|c|c|}
\hline $\begin{array}{l}\text { № об- } \\
\text { разца }\end{array}$ & $\begin{array}{l}\text { Марка алюми- } \\
\text { ниевого сплава }\end{array}$ & $\begin{array}{c}\text { Режим } \\
\text { обработки } \\
\end{array}$ & $\begin{array}{c}\text { Циклические напряжения в процессе } \\
\text { усталостных испытаний } \sigma, \text { МПа }\end{array}$ \\
\hline \multicolumn{4}{|c|}{ Разрушенные образцы } \\
\hline $\begin{array}{l}20 \\
23 \\
34 \\
21 \\
25 \\
36 \\
39 \\
36 \\
21 \\
34 \\
15 \\
23 \\
30 \\
37\end{array}$ & $\begin{array}{l}\text { B95 } \\
\text { B95 } \\
\text { B95 } \\
\text { B95 } \\
\text { B95 } \\
\text { B95 } \\
\text { B95 } \\
\text { Д16T } \\
\text { Д16T } \\
\text { Д16T } \\
\text { Д16T } \\
\text { Д16T } \\
\text { Д16T } \\
\text { Д16T }\end{array}$ & 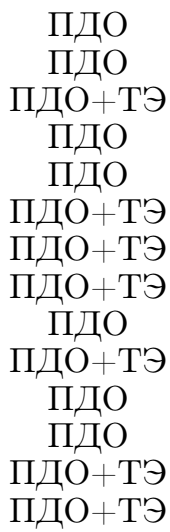 & $\begin{array}{c}171,5 \text { (сломался сам) } \\
132,3 \text { (доломали) } \\
127,4 \text { (сломался сам) } \\
122,5 \text { (сломался сам) } \\
132,3 \text { (доломали) } \\
120,05 \text { (сломался сам) } \\
112,7 \text { (сломался сам) } \\
149,45 \text { (доломали) } \\
156,8 \text { (сломался сам) } \\
147 \text { (доломали) } \\
176,4 \text { (сломался сам) } \\
154,35 \text { (сломался сам) } \\
171,5 \text { (доломали) } \\
149,45 \text { (доломали) }\end{array}$ \\
\hline \multicolumn{4}{|c|}{ Неразрушенные образцы } \\
\hline $\begin{array}{c}8 \\
17 \\
11 \\
27\end{array}$ & $\begin{array}{l}\text { В95 } \\
\text { В95 } \\
\text { Д16Т } \\
\text { Д16Т }\end{array}$ & $\begin{array}{c}\text { Неупр. } \\
\text { ПДО } \\
\text { Неупр. } \\
\text { ПДО }\end{array}$ & $\begin{array}{c}105,35 \\
200,9 \\
80,85 \\
156,8\end{array}$ \\
\hline
\end{tabular}

измерений оказывала неровность рельефа. В зоне 1 шаг измерения составлял 2000-3000 мкм, а измерения микротвёрдости в зоне 2 осуществлялись в направлении от области разрыва образца с шагом 100-300 мкм (первые 3 замера) и 700-800 мкм (последующие замеры) на длину 17-18 мм.

Измерение шероховатости проводилось на приборе Surftest SJ-201P. Шероховатость в зоне 1

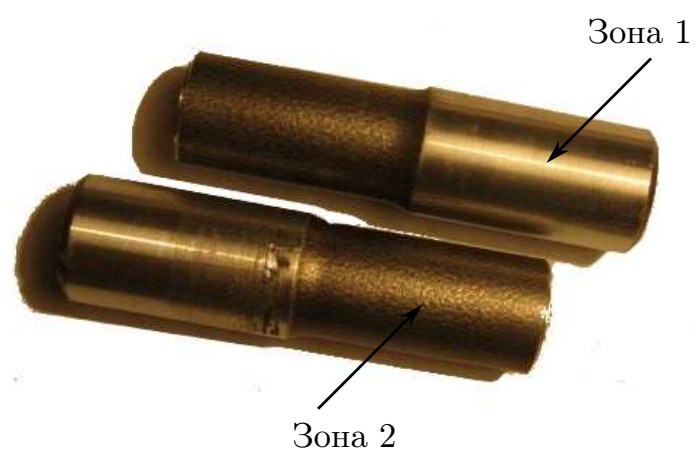

Рис. 3. Внешний вид разрушенных образцов характеризуют замеры $1-4$, а в зоне 2 - замер 5. Длина каждого замера - 12,5 мм. Исследование шероховатости производилось по следующим параметрам: $R_{z}$ - высота неровностей профиля по десяти точкам, $R_{q}$ - среднее квадратичное отклонение профиля.

Первый этап работы заключался в проведении макроструктурного анализа зоны разрушения. Особый интерес представляют трещины, образованные в упрочнённом слое и идущие вглубь от поверхности образца (рис. 4).

Данные по измерению микротвёрдости в анализируемых образцах и характерное распределение НК для сплава В95 представлены в табл. 3 и на рис. 5 и 7, а для Д16Т - в табл. 3 и на рис. 6 и 8. Следует отметить, что для каждого из сплавов вводилась собственная нумерация образцов. Поэтому в табл. 3 номера образцов для этих сплавов могут совпадать.

Выявлено, что микротвёрдость в зоне 1 (см. рис. 3) имеет практически однородный характер. Значения микротвёрдости для сплава В95 составляют 


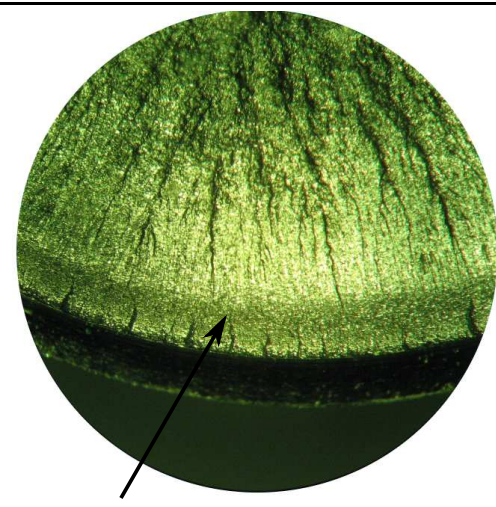

Упрочнённый слой

Рис. 4. Трещины в упрочнённом слое $(\times 56)$
200-280 НК, а для Д16Т - 150-250 НК.

Рассмотрим влияние пневмодробеструйной обработки на характер изменения микротвёрдости. В связи с упомянутой ранее неровностью рельефа на всех исследуемых образцах наблюдается сильный разброс значений микротвёрдости. Особое внимание следует обратить на влияние пневмодробеструйной обработки, применённой к образцам из сплава В95: микротвёрдость на образце 20 местами увеличивается до $3600 \mathrm{HK}$, на 23 - до $1050 \mathrm{HK}$, на 21 - до $2460 \mathrm{HK}$, на 25 - до 2200 НК. На образцах из сплава Д16Т также наблюдается рост микротвёрдости, но в меньшей степени (см.

табл. 3).

Термоэкспозиция, проведенная на образцах после пневмодробеструйной обработки, заметно снижает значения микротвёрдости в обоих рассмотренных сплавах. Практически во всех образцах (34, 36, 39 (сплав В95) и 36, 34, 30, 37 (сплав Д16Т)) термоэкспозиция приводит к падению микротвёрдости до исходного (неупрочнённого) состояния. Обратим внимание, что наиболее резкое снижение микротвёрдости заметно у сплава В95, что объясняется его малой теплостойкостью.

Усталостные испытания, проведенные на указанных образцах, привели к значительному росту микротвёрдости в зоне, непосредственно прилегающей к месту разрушения. Первые 4 замера, произведённые с шагами примерно 350, 150, 150, 500 мкм соответственно, указывают на то, что радиус области влияния пластической деформации составляет примерно 700-900 мкм.

Таблица 3

Разброс значений микротвёрдости в зонах 1 и 2

\begin{tabular}{c|c|c|c|c}
\hline $\begin{array}{c}\text { oo об- } \\
\text { разца }\end{array}$ & $\begin{array}{c}\text { Марка } \\
\text { сплава }\end{array}$ & $\begin{array}{c}\text { Режим об- } \\
\text { работки }\end{array}$ & $\begin{array}{c}\text { Микротвёрдость } \\
\text { в зоне 1, НK }\end{array}$ & $\begin{array}{c}\text { Микротвёрдость } \\
\text { в зоне 2, НК }\end{array}$ \\
\hline 20 & В95 & ПДО & $190-280$ & $450-3600$ \\
23 & В95 & ПДО & $190-285$ & $500-1050$ \\
34 & В95 & ПДО+ТЭ & $180-285$ & $50-300$ \\
21 & В95 & ПДО & $225-285$ & $225-2460,245-2200$ \\
25 & В95 & ПДО & $210-285$ & $400-2200,450-1800$ \\
36 & В95 & ПДО+ТЭ & $225-285$ & $200-285,210-240$ \\
39 & В95 & ПДО+ТЭ & $210-265$ & $225-340,225-290$ \\
36 & Д16Т & ПДО+ТЭ & $145-310$ & $210-310$ \\
21 & Д16Т & ПДО & $135-275$ & $210-285$ \\
34 & Д16Т & ПДО+ТЭ & $150-310$ & $245-330$ \\
15 & Д16Т & ПДО & $140-175$ & $200-790,210-700$ \\
23 & Д16Т & ПДО & $140-210$ & $200-270,210-270$ \\
30 & Д16Т & ПДО+ТЭ & $150-225$ & $200-445,200-375$ \\
37 & Д16Т & ПДО+ТЭ & $150-310$ & $225-330,185-320$ \\
8 & В95 & Неупр. & $220-265$ & $190-300$ \\
17 & В95 & ПДО & $185-285$ & $550-1040$ \\
11 & Д16Т & Неупр. & $140-285$ & $185-310$ \\
27 & Д16Т & ПДО & $140-185$ & $90-265$ \\
\hline
\end{tabular}




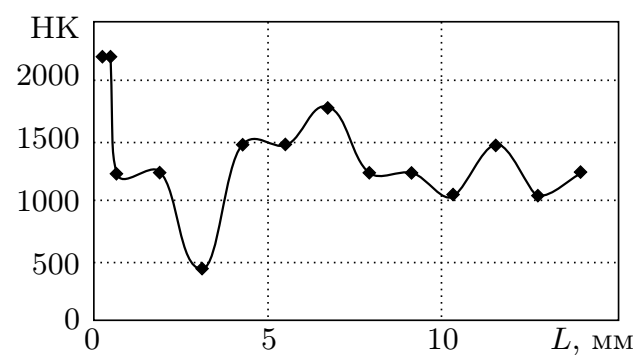

Рис. 5. Характерное изменение микротвёрдости в образце 25 (В95) в упрочнённой зоне (ПДО)

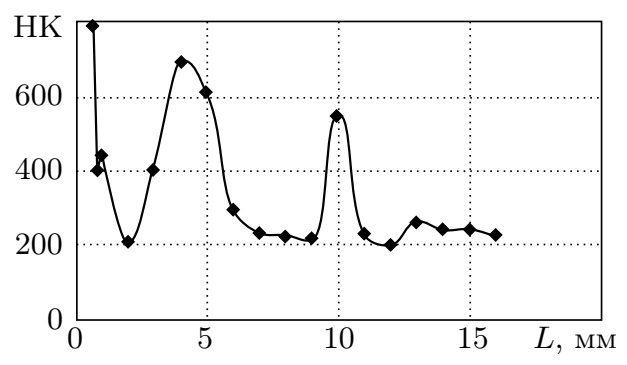

Рис. 6. Характерное изменение микротвёрдости в образце 15 (Д16Т) в упрочнённой зоне (ПДО)

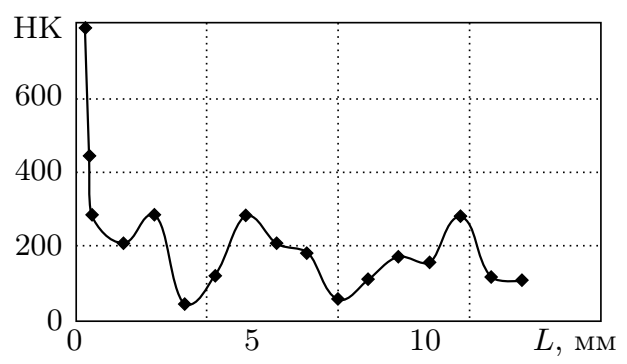

Рис. 7. Характерное изменение микротвёрдости в образце 34 (В95) в упрочнённой зоне (ПДО ТЭ)

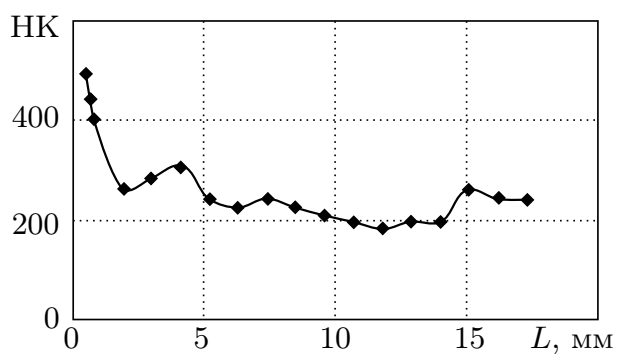

Рис. 8. Характерное изменение микротвёрдости в образце 37 (Д16Т) в упрочнённой зоне (ПДО ТЭ)

Микротвёрдость в этой зоне выросла в 1,5-3 раза (см. рис. 5-8). Наибольшие значения микротвёрдости в зоне 2 , указанные в табл. 3 , соответствуют именно этой области.

Результаты следующего этапа - измерения шероховатости - представлены в табл. 4 , которая содержит информацию по параметрам $R_{z}$ и $R_{q}$, полученную на замерах 1-4 (зона 2, см. рис. 3). Замер 5 (зона 1 ) был произведён на образцах 17 и 21 . В результате были получены следующие значения: $R_{z}=$ $=5,05$ мкм, $R_{q}=1,02$ мкм на образце 17 и $R_{z}=4,94$ мкм, $R_{q}=1,01$ мкм на образце 21.

Величины $R_{z}$ и $R_{q}$ на неупрочнённых образцах имеют сравнительно небольшие значения. Пневмодробеструйная обработка значительно искажает рельеф образцов и способствует сильному росту шероховатости, что наглядно представлено в табл. 4. Установлено, что термоэкспозиция не влияет на изменение шероховатости поверхности.

Выводы по работе. Проведённый комплексный анализ образцов как после пневмодробеструйной обработки, так и после пневмодробеструйной обработки с последующей термоэкспозицией, показал:

1) опережающее поверхностное пластическое деформирование приводит к существенному увеличению предела выносливости цилиндрических образцов с концентраторами напряжений из сплавов В95 и Д16Т по сравнению с неупрочнёнными образцами, что связано с существенными величинами остаточных напряжений на дне концентратора;

2) термоэкспозиция приводит к существенной релаксации наведённых остаточных напряжений как в гладких образцах, так и в упрочнённых 
Таблица 4

Результаты измерения шероховатости (мкм)

\begin{tabular}{c|c|c|r|r|r|c|c|c|r|r}
\hline № об- & Марка & Режим об- & \multicolumn{2}{|c|}{ Замер 1} & \multicolumn{2}{|c|}{ Замер 2 } & \multicolumn{2}{|c|}{ Замер 3 } & \multicolumn{2}{|c}{ Замер 4} \\
\cline { 4 - 9 } разца & сплава & работки & $R_{z}$ & $R_{q}$ & \multicolumn{1}{c}{$R_{z}$} & $R_{q}$ & $R_{z}$ & $R_{q}$ & \multicolumn{1}{c}{$R_{z}$} & $R_{q}$ \\
\hline 20 & В95 & ПДО & 27,20 & 5,77 & 25,31 & 5,44 & 20,75 & 4,87 & 18,99 & 4,35 \\
23 & В95 & ПДО & 23,93 & 5,29 & 21,30 & 4,76 & 21,34 & 5,01 & 22,91 & 5,53 \\
34 & В95 & ПДО+ТЭ & 20,39 & 4,87 & 22,53 & 4,97 & 16,27 & 3,41 & 19,94 & 4,33 \\
36 & Д16Т & ПДО+ТЭ & 26,54 & 5,63 & 24,47 & 5,83 & 21,01 & 4,99 & 23,94 & 5,85 \\
21 & Д16Т & ПДО & 21,18 & 4,89 & 23,81 & 5,39 & 24,28 & 5,33 & 24,44 & 5,92 \\
34 & Д16Т & ПДО+ТЭ & 28,18 & 6,39 & 24,80 & 5,37 & 25,35 & 5,43 & 21,99 & 4,63 \\
8 & В95 & Неупр. & 9,63 & 2,00 & 5,74 & 1,10 & 10,12 & 2,16 & 9,61 & 2,02 \\
17 & В95 & ПДО & 23,41 & 5,47 & 22,80 & 5,09 & 21,81 & 5,38 & 19,52 & 4,05 \\
11 & Д16Т & Неупр. & 6,31 & 1,19 & 9,91 & 2,00 & 14,74 & 3,25 & 8,26 & 1,53 \\
27 & Д16Т & ПДО & 23,10 & 5,39 & 24,16 & 6,09 & 23,03 & 5,31 & 21,45 & 4,91 \\
\hline
\end{tabular}

образцах с концентраторами напряжений, вызванной, по всей видимости, деформациями ползучести; следствием релаксации остаточных напряжений является падение величин приращения предела выносливости у образцов, подвергшихся термоэкспозиции;

3) макроструктурный анализ выявил наличие очага разрушения на всех исследуемых образцах и ручьистый излом в виде ступенек; в упрочнённом слое наблюдалось большое количество трещин;

4) пневмодробеструйная обработка значительно влияет на рост микротвёрдости (в особенности на образцах из сплава В95, где её значение возрастает на 1000-3000 НК по сравнению с исходной структурой), что связано, по всей видимости, не только с изменением струкутры материала в упрочнённом слое, но и с наличием приповерхностной зоны сжимающих остаточных напряжений, препятствующих внедрению индентора;

5) термоэкспозиция снижает значение микротвёрдости практически до исходного состояния, что особо заметно для образцов из сплава В95; это связано не только с релаксационными явлениями в самом упрочнённом металле, но и с релаксацией остаточных напряжений во времени и снижением (по модулю) их величины;

6) на расстоянии 700-900 мкм от зоны разрушения после усталостных испытаний сказывается влияние пластической деформации, которая приводит к сильному скачку микротвёрдости;

7) пневмодробеструйная обработка повышает параметры шероховатости поверхностного слоя; термоэкспозиция не оказывает влияния на данные параметры.

\section{БИБЛИОГРАФИЧЕСКИЙ СПИСОК}

1. Сулима А.М., Шулов В.А., Ягодкин Ю.Д. Поверхностный слой и эксплуатационные свойства деталей машин. М.: Машиностроение, 1988. 240 с. [Sulima A.M., Shulov V.A., Yagodnin R.D. Surface Layer and Service Properties of Machine Parts. Moscow: Mashinostroenie, 1988. 240 pp.]

2. Сулима А.М., Евстигнеев М. И. Качество поверхностного слоя и усталостная прочность деталей из жаропрочных и титановых сплавов. М.: Машиностроение, 1974. 250 с. [Sulima A.M., Evstigneev M.I. Surface-Layer Quality and Fatigue Strength of Parts of Heat-Resistant and Titanium Alloys. Moscow: Mashinostroenie, 1974. 250 pp.] 
3. Биргер И. А. Остаточные напряжения. М.: Машгиз, 1963. 232 с. [Birger I. A. Residual Stresses. Moscow: Mashgiz, 1963. 232 pp.]

4. Иванов С. И., Павлов В. Ф. Влияние остаточных напряжений и наклёпа на усталостную прочность // Пробл. прочности, 1976. № 5. С. 25-27; англ. пер.: Ivanov S. I. Pavlov V. F. The effect of residual stresses and cold working on fatigue strength // Strength of Materials. Vol. 8, no. 5. Pp. 529-531.

5. Павлов В.Ф. О связи остаточных напряжений и предела выносливости при изгибе в условиях концентрации напряжений // Изв. вузов. Машиностроение, 1986. № 8. С. 29 32. [Pavlov V.F. The relation between residual stress and fatigue limit in case of bending in conditions of stress concentration // Izv. vuzov. Mashinostroenie, 1986. no. 8. Pp. 29-32].

6. Иванов С.И., Шатунов М. П., Павлов В.Ф. Влияние остаточных напряжений на выносливость образцов с надрезом / В сб.: Вопросы прочности элементов авиачионных конструкций. Вып. 1. Куйбышев: КуАИ, 1974. С. 88-95. [Ivanov S. I., Shatunov M. P., Pavlov V.F. Effect of residual stresses on the fatigue of noth specimens / In: Problems of aircraft structure element strength. Issue 1. Kuibyshev: KuAI, 1974. Pp. 88-95].

7. Павлов В.Ф., Кирпичёв В. А., Иванов В. Б. Остаточные напряжения и сопротивление усталости упрочнённых деталей с концентраторами напряжений. Самара: СНЦ РАН, 2008. 64 c. [Pavlov V.F., Kirpichyov V.A., Ivanov V.B. Residual stresses and fatigue resistance of strengthened details with stress concentrators. Samara: SNC RAN, 2008. $64 \mathrm{pp}$.

8. Кравченко Б. А., Круиило В. Г., Гутман Г. Н. Термопластическое упрочнение-резерв повышения прочности и надёжности деталей машин. Самара: СамГТУ, 2000. 216 с. [Kravchenko B.A., Krutsilo V.G., Gutman G.N. Thermoplastic hardening as a reserve increase of strength and reliability of machine parts. Samara: SamGTU, 2000. 216 pp.]

9. Радченко В. П., Кирпичев В. А., Лунин В. В. Влияние пневмодробеструйной обработки и термоэкспозиции на остаточные напряжения и предел выносливости образцов с надрезами из сплавов В95 и Д16Т // Вестн. Сам. гос. техн. ун-та. Сер. Физ.-мат. науки, 2011. №3(24). C. 181-184. [Radchenko V. P., Kirpichev V. A., Lunin V. V. Influence of air shot blasting and temperature exposure on residual stresses and fatigue strength of notched specimens from alloys V95 and D16T// Vestn. Samar. Gos. Tekhn. Univ. Ser. Fiz.-Mat. Nauki, 2011. no. 3(24). Pp. 181-184].

10. Кирпичёв B. A., Букатый A. C. Влияние режимов пневмодробеструйной обработки на остаточные напряжения, микротвёрдость и сопротивление усталости / В сб.: Физика прочности и пластичности материалов: Tp. XVII Междунар. конф. Т. 1. Самаpa: СамГТУ, 2009. С. 109-111. [Kirpichev V.A., Bukatyi A.S. Air shot-blasting effect on residual stress, microhardness, and resistance to fatigue/ In: Physics of Strength and Plasticity of Materials. Vol. 1. Samara: SamGTU, 2009. Pp. 109-111].

11. Радченко В.П., Морозов А.П., Букатый А.С. Влияние многоцикловых усталостных испытаний на физико-механическое состояние упрочнённого слоя плоских образцов // Вестн. Сам. гос. техн. ун-та. Сер. Техн. науки, 2009. №3(25). С. 158165. [Radchenko V.P., Morozov A.P., Bukatyi A.S. Multicycle fatigue tests effect on the physical and mechanical state of the hardened layer of flat samples // Vestn. Samar. Gos. Tekhn. Univ. Ser. Teckhn. Nauki, 2009. no. 3(25). Pp. 158-165].

12. Радченко В. П., Морозов А. П. Экспериментальное исследование влияния пневмодробеструйной обработки, температурных выдержек и многоцикловых усталостных испытаний на физико-механическое состояние упрочнённого слоя цилиндрических образцов из сплавов В95 и Д16Т // Вестн. Сам. гос. техн. ун-та. Сер. Физ.-мат. науки, 2010. №5(21). C. 222-228. [Radchenko V.P., Morozov A.P. Experimental study of the effect induced by air shot-blasting processing, thermal exposition and high cycle fatigue tests on physical and mechanical condition hardening layer of cylindrical aamples of alloys V95 and D16T// Vestn. Samar. Gos. Tekhn. Univ. Ser. Fiz.-Mat. Nauki, 2010. no. 5(21). Pp. 222$228]$.

13. Иванов С. И. К определению остаточных напряжений в цилиндре методом колец и полосок / В сб.: Остаточные напряжения. Вып. 53. Куйбышев: КуАИ, 1971. С. 32-42. 
[Ivanov S. I. Determination of residual stresses in a cylinder by the ring and band method / In: Residual Stresses. Issue 53. Kuibyshev: KuAI, 1971. Pp. 32-42].

Поступила в редакцию 10/XII/2011;

в окончательном варианте - 10/II/2012.

MSC: 74R10; 74G70, 74-05

INVESTIGATION OF THE KINETICS OF PHYSICAL AND

MECHANICAL PROPERTIES OF HARDENED SAMPLES MADE OF B95 AND D16T ALLOYS DUE TIME-TEMPERATURE EXPOSITIONS AND MULTICYCLE FATIGUE TESTS

\section{V.P. Radchenko, V. V. Lunin, A.P. Morozov}

Samara State Technical University,

244, Molodogvardeyskaya st., Samara, 443100, Russia.

E-mails: radch@samgtu.ru; luloon@mail.ru, andre15@inbox.ru

The kinetics of residual stresses and physical and mechanical properties of the hardened air shot-blasting layer of smooth specimens and specimens with semicircular cuts of aluminum D16T and B95 alloys as a result of time-temperature expositions and multicycle fatigue tests is investigated. This research was done for symmetric loading cycle in terms of bending and tension-compression tests and the base of $10^{7}$ cycles. The growth of increment of the endurance limit of hardened parts with stress concentrators in comparison with non-reinforced specimens is established experimentally and by calculation. It is shown that the time-temperature exposition causes the relaxation of residual stresses and the reduction of increment of the endurance limit. In fact, surface plastic hardening significantly affects the growth of microhardness in comparison with samples unhardened. Microhardness decreases to values corresponding to unhardened sample after time-temperature expositions. The surface hardening increases the roughness layer and further time-temperature exposition and fatigue tests have no effect on these parameters. There is agreement between the calculated and experimental data.

Key words: surface hardening, cylindrical sample, semicircular cut, residual stresses, limit of resistance fatigue, time-temperature exposition, microhardness, roughness, strain hardening.

Original article submitted 10/XII/2011; revision submitted 10/II/2012.

Vladimir P. Radchenko (Dr. Sci. (Phys. \& Math.)), Head of Dept., Dept. of Applied Mathematics \& Computer Science. Valentin V. Lunin, Postgraduate Student, Dept. of Applied Mathematics and Computer Science. Andrey P. Morozov, Student, Dept. of Applied Mathematics \& Computer Science. 